\title{
Microinfiltração de materiais restauradores temporários usados durante o clareamento dental interno
}

\section{Microleakage of temporary restorative materials used during walking bleach technique}

\section{Marcia Carneiro VALERA}

Professora Adjunta - Disciplina de Endodontia da Faculdade de Odontologia de São José dos Campos - Universidade Estadual Paulista - UNESP - São José dos Campos - SP - Brasil

\section{Carlos Henrique Ribeiro CAMARGO}

Professor Doutor - Disciplina de Endodontia da Faculdade de Odontologia de São José dos Campos - Universidade Estadual Paulista - UNESP - São José dos Campos - SP - Brasil

\section{Adriano Urizzi TEIXEIRA}

Estagiário - Disciplina de Endodontia da Faculdade de Odontologia de São José dos Campos - Universidade Estadual Paulista - UNESP - São José dos Campos - SP - Brasil

\section{Samira Esteves Afonso CAMARGO}

Doutorando - Programa de Pós-Graduação em Biopatologia Bucal da Faculdade de Odontologia de São José dos Campos - Universidade Estadual Paulista - UNESP - São José dos Campos - SP - Brasil

\begin{abstract}
Resumo
O objetivo deste estudo foi avaliar a capacidade de diferentes materiais seladores temporários em prevenir a microinfiltração coronária durante o clareamento de dentes tratados endodonticamente. Foram utilizados 70 molares humanos íntegros que receberam abertura coronária padronizada e terapia simulando a técnica de clareamento. Os dentes foram divididos em 8 grupos ( 6 grupos experimentais e 2 grupos controle); sendo que nos grupos experimentais as cavidades de acesso foram seladas com Cavit (ESPE), Resina Composta TPH (Denstply), Cimento de Ionômero de Vidro (Vidrion R - SSWhite), IRM (Dentsply), Cimpat (Septodont) ou Cavitec (Kerr). O grupo controle negativo não recebeu abertura de acesso e no controle positivo as aberturas de acesso não foram restauradas. Os dentes foram termociclados $\left(5^{\circ} \mathrm{C}\right.$ a $55^{\circ} \mathrm{C}, 300$ ciclos) e a microinfiltração foi medida linearmente pela extensão de penetração do corante azul de metileno $2 \%$. As medidas das infiltrações foram avaliadas pelo modelo estatístico de Conover e pelo teste de Tukey (5\%). Os resultados mostraram melhor capacidade de selamento oferecida pelo Cimento de Ionômero de Vidro, Resina Composta e Cimpat, sem diferenças estatisticamente significantes ( $p>0,01$ ). Os maiores valores de infiltração foram verificadas com o IRM. Conclui-se que o cimento ionômero de vidro, a resina composta e o Cimpat são capazes de minimizar a microinfiltração e portanto podem ser utilizados como seladores temporários durante o clareamento.
\end{abstract}

\section{UNITERMOS}

Microinfiltração coronária; materiais restauradores temporários; clareamento dental.

\section{INTRODUÇÃO}

A técnica do clareamento interno mediato foi primeiramente introduzida por Spasser23 (1961) que preconizou a colocação de uma pasta formada de perborato de sódio misturado à água, deixada temporariamente dentro da câmara pulpar. Em 1963, Nutting \& Poe16 modificaram essa técnica e substituíram a água pelo Superoxol, alcançando um efeito sinérgico e Stewart24 (1965) descreveu a técnica termocatalítica em que uma bolinha de algodão saturada em Superoxol deveria ser colocada dentro da câmara pulpar e aquecida com instrumento quente. 
Atualmente, para o restabelecimento da cor dos dentes tratados endodonticamente, pode-se utilizar a técnica mediata (também chamada walking bleaching) (Rotstein et al.21, 1993; Vasconcellos et al.26, 2004), a técnica imediata (termo ou fotocatalítica) ou ainda a associação de técnicas para dentes com vitalidade pulpar (clareamento externo) e para dentes tratados endodonticamente (clareamento interno).

Na técnica mediata, o agente clareador deve permanecer por sete dias no interior da cavidade pulpar e após este período devem ser realizadas trocas semanais até a obtenção da cor desejada (Vasconcellos et al.26, 2004). Durante o tratamento clareador é necessário a colocação de um material restaurador provisório para minimizar possíveis infiltrações para o interior da cavidade pulpar.

Os materiais restauradores provisórios são de suma importância durante os procedimentos endodônticos, em especial quando se realiza o curativo de demora e após a obturação dos canais radiculares para prevenir a microinfiltração por fluídos orgânicos e bactérias do meio bucal e também prevenir a passagem de medicamentos intracanais do interior da câmara pulpar para o ambiente bucal (Pashley et al.19 1998; Zaia et al.28, 2002; Zmener et al.29, 2004; Balto et al.1, 2005). Para isto devem apresentar adesão às paredes da cavidade $\mathrm{e}$ um vedamento marginal satisfatório (Pashley et al.19 1998; Zmener et al.29, 2004).

Durante o tempo em que permanecem na cavidade os materiais restauradores provisórios sofrem alterações pela ação da variação do $\mathrm{pH}$ do meio, de forças mastigatórias e de variações térmicas podendo gerar falhas no vedamento marginal (Lee et al.14, 1993). Nos tratamentos de clareamento dentário isso se torna ainda mais crítico, pois a restauração provisória sofre pressão da liberação de gases, conseqüientes da reação de oxidação dos agentes clareadores, forçando-a para fora da cavidade (Rotstein et al.20, 1992; Rostein et al.22, 1995). Além disso, o material provisório deve permanecer intacto para manutenção e efetividade do agente clareador no interior da cavidade pulpar durante o tempo recomendado para a próxima troca deste agente.

Dentre os materiais seladores provisórios mais utilizados se destacam o IRM, Cavit, Cimpat, Cavitec, cimento ionômero de vidro, cimento ionômero de vidro modificado por resina e resina composta. A formulação do IRM é baseada em óxido de zinco e eugenol (Zmener et al.29, 2004), sendo que o processo de mistura pó e líquido libera grande quantidade de eugenol livre, que é volátil, resultando numa mistura pouco homogênea que associada a contração deste material pode levar a um pobre selamento marginal (Ganss \& Jung10, 1998; Deveaux et al.9, 1999).

O Cavit e o Cavitec são materiais higroscópicos que apresentam expansão linear resultante da absorção de água durante o endurecimento o que poderia melhorar o contato entre o material e a cavidade de acesso resultando na melhora do selamento marginal (Lee et al.14, 1993). O Cimpat também é um material temporário higroscópio que endurece rapidamente após ser inserido na cavidade sofrendo expansão durante o endurecimento (Holland et al.13, 1992).

O cimento ionômero de vidro convencional apresenta adesividade as estruturas dentárias, liberação de flúor, valores de contração de polimerização baixos o que pode permitir adequado selamento marginal. A resina composta é um material que, apesar de sofrer contração de polimerização, apresenta um selamento marginal satisfatório (OWENS et al. ${ }^{17}, 1998$; GOKAY et al. $\left.{ }^{11}, 2000\right)$.

Apesar das características e propriedades inerentes dos materiais seladores provisórios, os trabalhos que avaliam a capacidade de selamento destes materiais são bastante controversos, sendo que Blaney et al. ${ }^{4}$ (1981) e Barthel et al. ${ }^{2}$ (1999) verificaram uma maior capacidade de selamento oferecida pelo IRM quando comparado ao Cavit e Bobotis et al. ${ }^{5}$ (1989) demonstraram uma superioridade do Cavit em relação ao IRM no que diz respeito ao vedamento marginal.

Diante destas controvérsias, a proposta deste estudo foi verificar a capacidade de selamento marginal de seis materiais seladores provisórios, quando utilizados no clareamento dentário interno.

\section{Material e MÉTOdo}

Neste estudo foram analisados os materiais restauradores provisórios Cavit (ESPE, USA), Resina Composta (TPH - Dentsply LTDA, Brazil), Cimento de Ionômero de Vidro (Vidrion R - SSWhite, Brazil), IRM (Dentsply LTDA, Brazil), Cimpat (Septodont, France) e Cavitec (Kerr, USA).

Para isto foram utilizados setenta molares íntegros recentemente extraídos, armazenados até o momento de sua utilização em solução de formol $10 \%$. A abertura de acesso coronário foi padronizada com 4,0 x 4,0mm de largura utilizando a broca de fissura \# 170 até atingir a câmara pulpar, removendo todo o teto da cavidade pulpar. Sobre o assoalho da câmara pulpar foi colocada uma camada de guta-percha rosa de forma a obter-se $7 \mathrm{~mm}$ da superfície da guta-percha até a região mais baixa do ângulo cavo-superficial 
oclusal. Uma sonda periodontal marcada com caneta de retroprojetor foi utilizada para se garantir a medida padronizada da profundidade das cavidades. Sobre a guta-percha foi colocada uma camada de um milímetro de cimento de fosfato de zinco (SSWhite - Brazil) e os dentes foram levados para uma cuba umidificadora a $37^{\circ} \mathrm{C}$ por 12 horas. Com uma broca cilíndrica de \# 56 em baixa-rotação e instrumentos cortantes manuais, foi realizado um alisamento da superfície do cimento de fosfato de zinco padronizando-se $6 \mathrm{~mm}$ de sua superfície até a região mais baixa do ângulo cavo-superficial. Em seguida foi realizada a colocação de uma pasta dos agentes clareadores compostos por perborato de sódio tetra-hidratado (Terapêutica - Farmácia de manipulação - São José dos Campos SP) e peróxido de hidrogênio (Terapêutica - Farmácia de manipulação - São José dos Campos SP) e, sobre esta, um milímetro de papel absorvente, mantendo uma cavidade para colocação do material selador, com 4 mm de espessura, de acordo com as recomendações de Webber et al. ${ }^{27}$ (1978) (Figura 1).

Os dentes foram divididos em 8 grupos de acordo com o material selador a ser analisado, sendo 6 grupos experimentais $(n=10)$ e 2 grupos controle $(n=5)$. As cavidades de acesso do grupo um foram seladas com o cimento provisório Cavit, levados à cavidade por espátula de inserção \# 1 (Duflex - SSWhite, Brazil). No grupo 2, as cavidades foram seladas com Resina Composta TPH (Dentsply - Brasil) da seguinte maneira: confecção de uma base de $1 \mathrm{~mm}$ de Resina Composta (fotopolimerização por um minuto) seguido do condicionamento ácido do esmalte com ácido fosfórico, lavagem e secagem e aplicação do adesivo, fotopolimerização e preenchimento com resina. No grupo 3, as cavidades foram seladas com Cimento de Ionômero de Vidro (Vidrion R), seguindo-se a proporção pó/líquido indicada pelo fabricante e o material foi levado à cavidade utilizando-se de aplicador de hidróxido de cálcio (Duflex - SSWhite, Brazil). No grupo 4, as cavidades foram seladas com o cimento IRM, que foi espatulado segundo recomendações do fabricante e levado à cavidade com espátula \# 1 e condensado com bolinha de algodão. No grupo 5 , as cavidades foram seladas com o material restaurador provisório Cimpat; foi utilizada espátula \# 1 para inserção e gaze para condensação. No grupo 6, utilizou-se o material restaurador provisório Cavitec, que foi inserido na cavidade de modo semelhante ao grupo 5. No grupo 7 (controle negativo) os dentes não receberam abertura de acesso e foram impermeabilizados externamente com esmalte para unhas e cera pegajosa. No grupo
8 (controle positivo) os dentes receberam abertura coronária padronizada, forramento com guta-percha e $1 \mathrm{~mm}$ de cimento de fosfato de zinco, mas não receberam material clareador bem como material selador.

Os dentes foram estocados em umidade a $37^{\circ} \mathrm{C}$ por 24 horas e, em seguida, passaram pelo processo de ciclagem térmica completando 300 ciclos de $5^{\circ} \mathrm{C}$ a $55^{\circ} \mathrm{C}$ por 30 segundos cada, utilizando uma máquina de ciclagem térmica (Ética Equipamentos Científicos S.A. Brazil).

Depois da termociclagem, os dentes foram impermeabilizados externamente, exceto a $1 \mathrm{~mm}$ das aberturas de acesso, com duas camadas de esmalte para unhas e uma camada de aproximadamente 2 $\mathrm{mm}$ de cera pegajosa. Em seguida foram colocados em solução de azul de metileno $2 \%$ e o conjunto foi estocado em umidade $100 \%$ a $37^{\circ} \mathrm{C}$ por 7 dias. Após esse período, os dentes foram removidos do corante, lavados em água corrente por 24 horas e deixados secar naturalmente por 2 dias.

Os dentes foram seccionados ao meio no sentido mésio-distal para avaliação das infiltrações ocorridas na interface material selador/paredes cavitárias. As medidas das infiltrações foram realizadas com o auxílio de um Estereomicroscópio (Stemi 2000C - Zeiss, Germany) com ocular micrométrica e analisadas pelo modelo estatístico Conover. A região de rejeição foi determinada a partir de $\mathrm{p} \geq 0,05$.

\section{Resultados}

Os resultados foram submetidos ao teste de Tukey $(5 \%)$ e verificou-se que os dentes do grupo controle negativo não mostraram penetração do corante, enquanto que o controle positivo houve completa penetração do corante. As médias das infiltrações dos grupos experimentais foram avaliadas pelo modelo estatístico de Conover e podem ser observadas na Tabela 1.

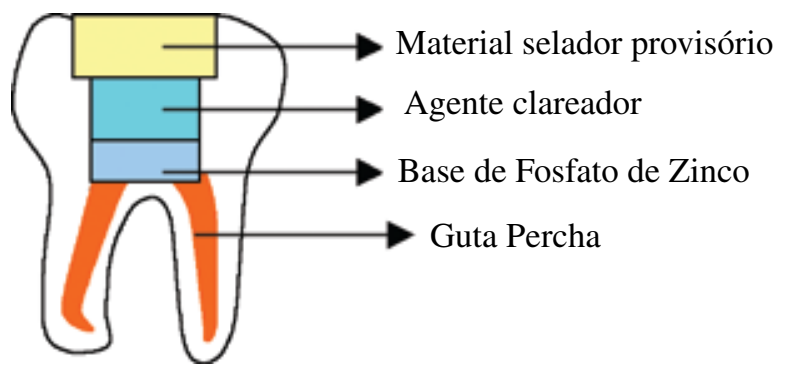

FIGURA 1 - Desenho esquemático da colocação do agente clareador e material selador provisório. 
Tabela 1 - Médias das infiltrações para cada grupo experimental

\begin{tabular}{|c|c|}
\hline Grupos experimentais & Médias \\
\hline Grupo 1 (Cavit) & $4,04 \mathrm{~mm}$ \\
\hline Grupo 2 (Resina Composta) & $1,45 \mathrm{~mm}$ \\
\hline Grupo 3 (Cimento de lonômero de Vidro) & $1,44 \mathrm{~mm}$ \\
\hline Grupo 4 (IRM) & $2,3 \mathrm{~mm}$ \\
\hline Grupo 5 (Cimpat) & $1,6 \mathrm{~mm}$ \\
\hline Grupo 6 (Cavitec) & $3,1 \mathrm{~mm}$ \\
\hline
\end{tabular}

Os melhores resultados foram apresentados pelo Cimento de Ionômero de Vidro, Resina Composta e Cimpat, entretanto sem diferenças estatísticas entre si. O IRM, embora tenha apresentado resultados inferiores, não diferiu estatisticamente da Resina Composta, Cimento de Ionômero de Vidro e Cimpat. Os piores resultados foram encontrados no Cavitec e Cavit que não foram estatisticamente diferentes entre si, mas foram diferentes dos grupos da Resina Composta, Cimento de Ionômero de Vidro e Cimpat (Tabela 2).

\section{Dıscussão}

Vários estudos têm avaliado a capacidade de selamento de materiais restauradores temporários em Endodontia (CHOHAYEB \& BASSIOUNY ${ }^{6}$, 1985; DEVEAUX et al. ${ }^{8}, 1992$; BARTHEL et al. ${ }^{2}$, 1999; ZMENER et al. ${ }^{29}, 2004$; BALTO et al. ${ }^{1}, 2005$ ). Entretanto, não se encontram trabalhos que avaliam a infiltração de corantes em materiais restauradores provisórios durante a técnica de clareamento intracoronário.
Acredita-se que o agente clareador contendo peróxido de hidrogênio se decompõe em radicais livres formando oxigênio molecular e água, que penetram através da matriz orgânica do esmalte, dentina e mesmo na interface entre o material restaurador e o dente, podendo prejudicar o selamento marginal das restaurações (ROSTEIN et al. ${ }^{22}$, 1995., HEGEDÜS et al. ${ }^{12}$, 1999; BENETTI et al. ${ }^{3}$, 2004).

Os resultados deste trabalho mostraram que o melhor selamento foi obtido pela Resina Composta e pelo Cimento Ionômero de Vidro, seguidos pelo Cimpat. Apesar dos estudos utilizando a resina composta mostrarem que a mesma permite passagem do agente clareador para o interior da polpa (BENETTI et al. $\left.^{3}, 2004\right)$, o avanço da tecnologia adesiva já mostrou grande melhora no selamento destes materiais adesivos (OWENS et al. $\left.{ }^{17}, 1998\right)$, especialmente quando se compara a resina composta a outros materiais restauradores como o cimento ionômero de vidro (GOKÄY et al. $\left.{ }^{11}, 2000\right)$.

No presente estudo, a Resina Composta foi colocada diretamente sobre o papel absorvente impregnado pelo agente clareador, o que pode ter impedido sua completa polimerização, devido inibição na presença do oxigênio (CHRISTENSEN $\left.{ }^{7}, 1996\right)$. Entretanto, a porção mais coronal correspondente ao maior volume do material restaurador não sofreu interferência do agente clareador, uma vez que utilizou-se a técnica de inserção e polimerização incremental, fato este que resultou em menor infiltração observada com este material.

Neste estudo, a microinfiltração verificada com o Cimento Ionômero de Vidro foi muito semelhante à observada com a Resina Composta, sendo que este resultado pode ser devido às características do Cimento

Tabela 2 - Resultados do teste de Tukey (5\%) para os dados quantitativos

\begin{tabular}{lc}
\hline Grupos experimentais & Grupos Homogêneos* \\
\hline Grupo 2 (Resina Composta) & A \\
Grupo 3 (Cimento de lonômero de Vidro) & A \\
Grupo 4 (IRM) & A \\
Grupo 5 (Cimpat) & A \\
Grupo 1 (Cavit) & \\
Grupo 6 (Cavitec) & B \\
\hline
\end{tabular}

*Médias seguidas de letras iguais na mesma coluna não diferem estatisticamente 
Ionômero de Vidro em aderir-se quimicamente à estrutura dental (MALDONADO et al. ${ }^{15}$, 1978) promovendo um bom selamento marginal. Este bom selamento também foi confirmado por Barthel et al. ${ }^{2}$ (1999) que verificaram que o cimento ionômero de vidro foi capaz de impedir a infiltração coronária de bactérias de forma mais efetiva que o Cavit e o IRM.

Porém, os resultados relatados por Zaia et al. ${ }^{28}$ (2002) não mostraram bom selamento coronário para o cimento ionômero de vidro (Vidrion $\mathrm{R}$ ) e adesivo dentinário Scotchbond, quando comparados ao Coltosol e IRM, relatando que apesar do melhor selamento proporcionado pelos dois últimos, todos os materiais testados não foram capazes de impedir a infiltração coronária. Vasconcellos et al. ${ }^{26}$ (2004) compararam a capacidade seladora de cinco materiais (Vivaglass, cimento de zinco, Coltosol, cimento resinoso e Ketac Fill) utilizados no clareamento interno e verificaram que, com exceção do Coltosol, todas as outras bases foram ineficazes quanto ao vedamento cervical.

O Cavit, apesar ser um material higroscópico, apresentou os maiores índices de infiltração. Deve-se considerar que neste estudo foi utilizado o agente clareador no interior da câmara pulpar que libera radicais livres que podem ter penetrado na interface dente/material restaurador antes do endurecimento do selador provisório impedindo o contato do material com as paredes da cavidade de acesso. E, embora, Barthel et al. ${ }^{2}$ (1999) não tenham utilizado agente clareador, os autores também verificaram pobre selamento com o Cavit, observando infiltração bacteriana inclusive no interior da obturação do canal em 13 das 20 amostras seladas com este material. Já, Balto et al. ${ }^{1}(2005)$ verificaram que o Cavit mostrou-se efetivo como material selador frente infiltração bacteriana.

Neste estudo, o pobre selamento marginal observado com o IRM está de acordo com outros trabalhos (BOBOTIS et al. ${ }^{5}$, 1989; BARTHEL et al. ${ }^{2}$, 1999, DEVEAUX et al. ${ }^{8}$, 1992., LEE et al. ${ }^{14}$, 1993; ZMENER et al. ${ }^{29}, 2004$; BALTO et al. ${ }^{1}, 2005$; TULUNOGLU et al. $\left.{ }^{25}, 2005\right)$. O processo de mistura do pó e líquido do IRM pode resultar numa mistura pouco homogênea que associada a contração deste material pode levar ao pobre selamento marginal (DEVEAUX et al. ${ }^{9}$, 1999; BALTO et al. ${ }^{1}$, 2005). Além disto, o preparo do IRM de acordo com as recomendações do fabricante, como realizado neste trabalho, leva a uma mistura com grande quantidade de eugenol livre, que é volátil e, ao preencher a cavidade, a massa de material restaurador pode não ser homogênea resultando em diferenças no selamento marginal dos diferentes espécimes.
Ainda o uso do IRM em dentes que serão posteriormente restaurados com resina composta poderá ser contra-indicado devido à possibilidade do IRM inibir a polimerização dos compósitos (DEVEAUX et $\mathrm{al}^{8}, 1992$; TULUNOGLU et al. $\left..^{25}, 2005\right)$. Entretanto, Ganss \& Jung ${ }^{10}(1998)$, advertem que o pré-tratamento da dentina com materiais temporários com ou sem eugenol pode ter efeito adverso na força de união e resistência ao cisalhamento de materiais adesivos.

O Cavitec, material selador temporário que não foi utilizado em estudos prévios, apresentou grande deficiência no vedamento marginal. Embora seja um material que absorve água durante o endurecimento, verificou-se que o mesmo apresentava-se quebradiço, com penetração de corante não apenas na interface material/paredes cavitárias, mas também na massa do material selador, mostrando-se impróprio para utilização nos procedimento de clareamento.

O Cimpat também é um material temporário higroscópio que endurece rapidamente após ser inserido na cavidade, sendo assim, apesar da presença do agente clareador, ocorreu contato entre este material e as paredes da cavidade de acesso levando a resultados satisfatórios neste trabalho e em outros como o de Holland et al. ${ }^{13}(1992)$.

Neste estudo, os materiais foram inseridos na cavidade com $4 \mathrm{~mm}$ de profundidade para minimizar interferências durante as funções mastigatórias e conseqüentemente diminuir a microinfiltração, sendo preconizado de 3,5 a $4 \mathrm{~mm}$ de espessura por Webber et al..$^{27}$ (1978) e Pais et al. ${ }^{18}$ (1999). Pode-se verificar que dos materiais testados, o Cimento de Ionômero de Vidro, a Resina Composta e o Cimpat podem ser utilizados como seladores temporários nos casos de clareamento de dentes tratados endodonticamente.

Deve-se ressaltar, no entanto, que estes resultados referem-se a uma condição in vitro. Clinicamente, o selamento marginal das restaurações pode ser influenciado pelas forças mastigatórias podendo aumentar com o tempo (LEE et al. $\left.{ }^{14}, 1993\right)$, embora, os materiais tenham sido inseridos com uma adequada espessura na cavidade.

\section{Conclusão}

O cimento ionômero de vidro, a resina composta e o Cimpat são capazes de minimizar a microinfiltração e portanto podem ser utilizados como seladores temporários durante o clareamento de dentes tratados endodonticamente. O IRM apresentou os maiores valores de microinfiltração e assim deve ser evitado como material selador temporário. 


\begin{abstract}
The aim of this study was to evaluated the sealing ability of several temporary restorative materials during the walking bleaching in teeth treated endodontically. Seventy human molars were used in this study. The teeth received a simulated dental bleaching treatment and were divided in 8 groups ( 6 experimentals and 2 control groups). At the experimentals groups the coronal access was filling by: Cavit (ESPE), Composite Resin TPH (Dentsply), Glass Ionomer cement (Vidrion R - SSWhite), IRM (Dentsply), Cimpat (Septodont) ou Cavitec (Kerr). The negative control group didn't recived coronal access and at positive control the coronal access was not filled. The teeth were thermocycled $\left(5^{\circ} \mathrm{C}\right.$ to $55^{\circ} \mathrm{C} 300$ cycles). The microleakage was recorded linearly by maximum penetration of the metilene blue $2 \%$. The results showed the best sealing by the glass ionomer cement, composite resin and Cimpat, without statistical difference between them ( $p>0,01)$. The highest leakage was observed by IRM.
\end{abstract}

\title{
UNITERMS
}

Coronal microleakage; temporary restorative materials; dental bleaching.

\section{REFERÊNCIAS}

1. Balto H, Al-Nazhan S, Al-Mansour K, Al-Otaibi M, Siddiqu Y. Microbial leakage of Cavit, IRM, and Temp Bond in post-prepared root canals using two methods of gutta-percha removal: an in vitro study. J Contemp Dent Pract. 2005 Aug 15;6(3):53-61.

2. Barthel CR, Strobach A, Briedigkeit H, Gobel U, Roulet JF. Leakage in roots coronally sealed with different temporary fillings. J Endod. 1999; 25(11):731-4.

3. Benetti AR, Valera MC, Mancini MN, Miranda CB, Balducci I. In vitro penetration of bleaching agents into the pulp chamber. Int Endod J. 2004 Feb; 37(2):120-4.

4. Blaney TD, Peters DD, Setterstrom J, Bernier WE. Marginal sealing quality of IRM and Cavit as assessed by microbial penetration. J Endod. 1981 Oct;.7(10):453-7.

5. Bobotis HG, Anderson RW, Pashley DH, Pantera EA. A microleakage study of temporary restorative materials used in endodontics. J Endod. 1989 Dec; 15(12):569-72.

6. Chohayeb AA, Bassiouny MA. Sealing ability of intermediate restoratives used in Endodontics. J Endod. 1985 Jun; 11(6):241-4.

7. Christensen GJ. Tooth sensitivity related to class I and II resin restorations. J Am Dent Assoc. 1996 Apr; 127(4):497-8.

8. Deveaux E, Hildelbert P, Neut C, Boniface B, Romond C. Bacterial microleakage of Cavit, IRM and Term. Oral Surg Oral Med Oral Pathol. 1992 74:634-43.

9. Deveaux E, Pierre H, Neut C, Romond C. Bacterial microleakage of cavit, IRM, Term, and Fermit: a 21-day in vitro study. J Endod. 1999 Oct; 25(10):653-9.

10. Ganss C, Jung M. Effect of eugenol - containing temporary cements on bond strength of composite to dentin. Oper Dent 1998; 23(2):55-62.

11. Gokay O, Yilmaz F, Akin S, Tuncbilek M, Ertan R. Penetration of the pulp chamber by bleaching agents in teeth restored with various restorative materials. J Endod. $2000 \mathrm{Feb}$;26(2):92-4.

12. Hegedüs C, Bistey T, Flora-Nagy E, Keszthelyi G, Jenei A. An atomic force microscopy study on the effect of bleaching agents on enamel surface. J Dent. 1999 Sep;27(7):509-15.

13. Holland R, Dezain Jr E, Yanagihara VYY, Souza V, Saliba O. Avaliação da infiltração marginal de materiais seladores temporários. RGO 1992; 40(1):29-32.

14. Lee YC, Yang SF, Hwang YF, Chueh LH, Chung KH. Microleakage of endodontic temporary restorative materials. J Endod. 1993 Oct; 19(10):516-20.

15. Maldonado A, Swarte ML, Phillips RN. An glass ionomer. J Am Dent Assoc. 1978 May; 95(5):785-91.

16. Nutting EB, Poe GS. A new combination for bleaching teeth. J South Calif Dent Assoc. 1963 Sept; 31(9):289-91.
17. Owens BM, Halter TK, Brown DM. Microleakage of tooth-colored restorations with a beveled gingival margin. Quintessence Int. 1998 Jun;29(6):356-61.

18. Pais S, Yang S, Sue W, Chueh L, Rivera EM. Microleakage between endodontic temporary restaurative materials placed at different times. J Endod. 1999 Jun; 25(6):453-56.

19. Pashley EL, Tao L, Pashley DH. The sealing properties of temporary filling materials. J Prosth Dent. 1998 Sep; 60(3):292-6.

20. Rotstein I, Lehr Z, Gedalia I. Effect of bleaching agents on inorganic components of human dentin and cementum. J Endod. 1992 Jun;18(6):290-3.

21. Rotstein I, Mor C, Friedman S. Prognosis of intracoronal bleaching with sodium perborate preparation in vitro: 1-year study. J Endod. 1993 Jan;19(1):10-2.

22. Rostein I, Cohenca N, Mor C, Moshonov J, Stabholz A. Effect of carbamida peroxide and hidrogen peroxide on the surface morphology and zinc oxide levels of IRM fillings. Endod Dent Traumatol. 1995 Apr; 11(6):279-82.

23. Spasser HF. A simple bleaching techique using sodium perborate. NY St Dent J. 1961 Aug./Sept; 27(7):332-4.

24. Stewart GG. Bleaching discolored pulpless teeth. J Am Dent Assoc. $1965 ; 70(2): 325-28$.

25. Tulunoglu O, Uctasli MB, Ozdemir S. Coronal microleakage of temporary restorations in previously restored teeth with amalgam and composite. Oper Dent. 2005 May-Jun;30(3):331-7.

26. Vasconcelos WA, Ribeiro FSV, Fabrini AES, Silveira FF, Albuquerque RC. Avaliação da capacidade de vedamento proporcionado por diferentes materiais para confecção de tampão cervical. JBC 2004; 8(46):313-7.

27. Webber RT, Del Rio CE, Brady JM, Segall RO. Sealing quality of a temporary fillings material. Oral Surg Oral Med Oral Pathol. 1978 Jul; 46(1):123-30.

28. Zaia AA, Nakagawa R, Quadros I, Gomes BPFA, Ferraz CCR, Teixeira $\mathrm{FB}$, et al. An in vitroevaluation of four materials as barriers to coronal microleakage in root-filled teeth. Int Endod J. 2002; 35:729-34.

29. Zmener O, Banegas G, Pameijer CH. Coronal microleakage of three temporary restorative materials: an in vitro study. J Endod. 2004 Aug;30(8):582-4.

Recebido em: 10/10/05 Aprovado em: 13/12/05

Correspondência: Prof $^{a}$. Marcia Carneiro Valera Av Francisco José Longo, 777 - Jardim São Dimas 12245-000 - São José dos Campos - SP - Brasil e-mail: marcia@fosjc.unesp.br 